\title{
Piloting a multidisciplinary and integrated road traffic injury surveillance system in Kaduna Metropolis, Kaduna Nigeria.
}

Obafemi Joseph Babalola ( $\sim$ drfemibabs@yahoo.com )

\section{Research Methods}

Keywords: Traffic, Injury, Surveillance System, Integrated, Multidisciplinary, Nigeria

Posted Date: May 28th, 2020

DOI: https://doi.org/10.21203/rs.3.rs-30715/v1

License: (9) (i) This work is licensed under a Creative Commons Attribution 4.0 International License.

Read Full License 


\section{Abstract \\ Background}

African has the highest road fatality rate per 100,000 population, but Nigeria accounts for a quarter of the World Health Organization Afro region road traffic injury (RTI) related deaths. The Nigeria Federal Road Safety Corps (FRSC) is the sole agency for RTI surveillance. RTI data generated from a single source is inadequate, under-reported, and defective for effective planning to achieve SDG 3.6 target. This pilot study aimed to describe under-reporting of single RTI surveillance data source by FRSC, and feasibility of multidisciplinary and integrated RTI surveillance systems in Kaduna metropolis, Nigeria.

\section{Methods}

The WHO Injury Surveillance Guideline, and Centres for Disease Control and Prevention Surveillance Training Manual were adapted for this study. Selected RTI reporting sites for this study were FRSC, police, and three major health facilities. Trained data collectors used a pretested RTI data tool adapted from the existing tools to collect information on road traffic crashes and the injured from February - July 2016. Data linked by the deterministic method were merged, duplicates removed, and analysed for frequencies, proportions, and Chi-square odds ratio for associations between exposure variables and moderate to fatal injury. Statistical significance for all calculations was set at $p$-Value $<0.05$.

\section{Results}

Of the 667 road traffic crashes (RTC), FRSC reported 103 (15.4\%). Of the 1,062 people injured, FRSC and Police reported $183(17.2 \%)$, and 381 (35.9\%) respectively, pedestrians were $180(17 \%)$, and $374(35.2 \%)$ were in 25-34 years age group. Overall, 110 (10.4\%) were fatally injured and died including $62.7 \%$ $(69 / 110)$ who were initially rescued alive from the crash site. Among the 252 motorcycle riders, protective helmet was used by $26(10.3 \%)$. Also, 136 (26.4\%) vehicle users from 516 , used a seat belt during the crash. Moderate to fatal injury was associated with being a vehicle operator during the crash (OR 1.7, C.I. $1.3-2.2, p=0.000$ ).

\section{Conclusion}

Road traffic crashes and injuries were under-reported with single source RTI surveillance systems common to low and middle - income countries like Nigeria. However, a multidisciplinary and integrated RTI surveillance system is feasible and recommended to generate quality data for action.

\section{Background}


Road traffic injury (RTI) is the unplanned occurrence of auto crashes that may result in injuries, loss of lives and property [1]. It is the most common cause of unintentional injury [2] and was the eighth leading cause of death globally for all age groups and the leading cause of death for children and young people 5-29 years of age [3]. RTI causes severe socio-economic burden to individuals, households, and the whole nation [4]. It caused 1.35 million deaths [3] and injured 50 million people annually, with aged 1544 accounting for half of the injured [5-7]. Low and middle-income countries account for $90 \%$ of global mortality due to RTI with a disproportionate number of vehicles $[3,6]$. The WHO African region has the highest rate of road fatality rate per 100,000 population among WHO regions and reported $20 \%$ of global road traffic deaths with 272,000 deaths in 2018 [8]. Nigeria accounts for more than twenty-five per cent of RTI related deaths in WHO Afro region $[9,10]$ and estimated rate of road traffic death per 100,000 was 20.5 compared to 26.6 in Afro region $[8,11]$. In Nigeria, Kaduna State ranked 5th on RTI-related deaths per 1000 in 2011-2012 and reported 454 deaths from 426 road crashes [10].

To improve global road safety, the United Nation 64th session declared "Decade of global action for road safety with the aim to reduce the increasing trend in road traffic death [12]. This was further strengthened in the Brasilia declaration [13] and to ensure healthy lives and promote well-being for all at all ages, the sustainable development goal (SDG) target 3.6 seeks to halve the global number of road traffic deaths by 2020 [4]. Therefore, to monitor and evaluate the progress toward achieving this goal, the WHO Afro region recommended strengthening data collection among countries to identify gaps in the system and deliver well-tailored interventions for improvement $[8,9]$.

Succinctly, in most African countries, RTI surveillance data is poor. They depend on single RTI data source, i.e., police report, but $16 \%$ of these countries use multiple data sources like the police and health records [9]. Like most of the counties in Africa, RTI data surveillance in Nigeria was saddled with a sole agency, the Federal Road Service Corps (FRSC) who was responsible for RTI surveillance and reporting. In addition, police motor traffic departments also involved in RTI data collection, especially if litigation is likely, and most minor RTI cases will present to health facilities while some that occurred in the community are not reported. These RTI data from the police and health facilities are rarely integrated with the FRSC as indicated in 2015 Global Safety Report on Road Safety, where Nigeria reported 6,450 road traffic-related deaths which were lower than 35,641 deaths estimated by WHO using vital registration data [4].

Currently, efforts are being made by FRSC to establish a comprehensive and integrated RTI surveillance in Nigeria. This pilot study was developed to describe the feasibility of integrating RTI surveillance data from FRSC, Police and health facilities. This will generate a robust and reliable RTI data needed for information to plan and formulate policy, to advocate for funding to support RTI surveillance to achieve sustainable development goal 3.6 target (SDG-3.6) of halving road traffic deaths and injuries by 2020 in Nigeria. The SDG 3.6 may not be achieved if no drastic action is instituted [3]. There is no known similar study in Nigeria. The study aimed to describe a pilot study on the feasibility of integrating RTI data from the Police, health facility and FRSC for improving RTI surveillance in Nigeria. 


\section{Methods}

The method as outlined in Injury surveillance guidelines [14] and surveillance training manual [15] of the World Health Organization and Centres for Disease Control and Prevention was adapted for this study.

\section{The Study Setting}

Kaduna State, North-Western Nigeria, has 23 local governments with Kaduna metropolis as its capital. Kaduna is an industrial centre and a former administrative seat of Northern Nigeria. It is the third-largest city in Nigeria with 1.9 million people as the estimated population in 2015. This cosmopolitan city, covering an area of $3,080 \mathrm{Km} / \mathrm{m} 2$ is about $200 \mathrm{~km}$ from Abuja the federation capital city. Being a transit town from Abuja the nation's capital to the 18 Northern states, it has a high volume of vehicular movement with 3 major highways traversing the metropolis. Although the city is rapidly growing in motor vehicle ownership, in 2006 it witnessed a considerable increase in the average of 4,000 vehicular registration per annum [16], mostly using two-, three- and four-wheel vehicles for transportation. In 2013, the use of a protective helmet by motorcyclist was legalized but was not enforced in the state.

\section{RTI Stakeholders' Identification And Collaboration}

The identified stakeholders of RTI surveillance in Kaduna Metropolis are FRSC, health workers at Accident and Emergency (A \& E), Pathology/mortuary, Police Motor Traffic Division, Road transport workers, Ministry of Roads and Transport, Ministry of Health, Journalists, Civil Society Organisations and the public. Following the advocacy visits, the stakeholders brainstorm and developed an RTI surveillance mechanism, design data tools, defined monitoring indicators and met every 3 months to review the progress of the study. A case was defined as any person in Kaduna metropolis killed or died within 30 days because of injuries incurred from a collision on a public road involving at least one moving vehicle. The cases were identified, investigated and reported by the designated RTI reporting site $[17,18]$.

The following indicators were developed for monitoring:

1. Total number of road traffic crashes that occurred within a reporting month

2. Total number of people injured following road traffic crashes (minor, severe and fatal)

3. The proportion of the people injured that resulted from a crash without no primary object of a collision that occurred within a reporting month. The denominator is the total number of the injured.

4. The proportion of the injured following a crash that was transferred by the Police to the health facility within a reporting month. The denominator is the total number of the injured.

5. The proportion of the injured following a crash that was transferred by the FRSC to the health facility within a reporting month. The denominator is the total number of the injured. 
6. The proportion of the injured that used safety element during the crash. The denominator is the total number of the injured.

7. The proportion of those that died (fatally injured) following road traffic injury within a reporting month. The denominator is the total number of the injured.

8. The proportion of death that occurred at the health facility among the fatally injured within a reporting month. The denominator is the total number of fatally injured.

9. Timeliness: Proportion of reporting sites that sends the monthly data before the end of five working days of the succeeding month.

10. Completeness: Proportion of reporting sites that send a completed monthly RTI data, including zero reporting.

\section{RTI Data Collection Sources}

Three major health facilities with high volumes of road traffic injury cases in the Kaduna metropolis, Kaduna State Nigeria e.g., Barau Dikko Teaching Hospital (BDTH), St. Gerald Catholic Hospital (SGCH) and 44 Army Reference Hospital were purposefully selected health facilities for this study. Other sectors or disciplines selected were The Police Motor Traffic Division (MTD) and lastly, the Federal Road Safety Corps (FRSC).

\section{Data Tool}

Using the existing FRSC and police motor traffic division's RTI surveillance data collection tools, three data collection tools were developed. Two of the data tools were paper-based and the last was electronic. The paper-based individual case-based form was used at the health facility and consisted of three sections; a section for demographic information like name, age, sex, address, occupation, crash number, case number, reporting date and name of reporting health facility; section on injury include variables such as date of the crash, time, location, mode of travelling, what the vehicle collided with, type of location (highway, road, street), and disposal from the crash site and injury description were reported; the last and third section includes post-crash care which includes information on the date of presentation at the health facility, time of presentation, time is seen by the healthcare worker, prior presentation at the health facility and where, who transported the victim to the health facility, vital signs on presentation (pulse rate, blood pressure, temperature, respiration rate), preliminary diagnosis, emergency treatment and disposal or outcome at Accident \& Emergency were reported.

The second paper-based data tool was a monthly summary form. It includes such variables as the name of reporting health facility, date and time of the crash, number of the crash, age and sex of the injured and outcome of the crash (fatal, serious or minor), the crash site, the probable cause of accident and type of vehicle involved and the outcome. The electronic form is an excel Microsoft spreadsheet used to line-list RTI cases as seen by each reporting facility. Data were sent monthly to the data manager before the end 
of the first five working days of the subsequent month and principal investigator provided feedback monthly.

Injury severity was classified into mild, moderate, and severe or fatal. The mild injury was an injury sustained following road crashes without hospitalization of the injured e.g., bruises or abrasion, contusion, minor lacerations, and other soft tissue injuries. Moderate injury included any fracture, spinal cord injury, loss of consciousness or vital-organ involvement that warranted a stay in the hospital, while severe or fatal injury was life-threatening conditions that resulted in death. The primary object of the collision was an object i.e., vehicles, road pavement, pedestrian, stationary objects like poles, packed vehicles etc., that a moving vehicle collided with during the crash and road was classified according to the number of lanes i.e., four- and two-lane roads.

\section{Data collection}

Data were collected between February to July 2016 by trained data collectors and their supervisors. Data were collected at the crash sites by the police and FRSC and move the victims to the health facility. At the health facilities, data collectors interviewed anyone presenting with RTI after they had been seen and clinically stabilised by the clinicians. In cases where the injured had been admitted into the wards within the hospital, data were collected at the ward if stable. Otherwise if unstable, dead, referred to other health facilities not included in the piloting surveillance or had been discharged before the interview, the data were extracted from the victim's health records. Also, data collectors actively search registers at A\&E, General Outpatient Department (GOPD), autopsy or pathology department and mortuary to retrieve information on RTI cases. For RTI cases brought to the health facilities by the Police and FRSC data were collaborated between the two reporting sectors and duplicates marked in the line-listing of each sector.

At the end of each day, data collected were line listed on the Microsoft excel sheet and sent to data manager at the end of each month and together with individual case-based form, summary form and the excel line-list (e-copy form) latest within the five working days of succeeding month and duplicated copies were removed from the database. Zero reporting was allowed, and missing variables in the health records were coded " 99 ". The supervisors in each reporting site validated the RTI data by checking for data completeness of the individual case-based form compared with the excel line list before submitting to the data manager.

\section{Data analysis}

The data were cleaned and uniformly standardized by removing any abbreviations, hyphens, incorrectly written alphabets, formatting date of birth and code "99" for missing variables. The data manager linked datasets from the health facilities with RTI data from the police and FRSC using a deterministic or rulebased method. The linkage was based on an agreement between four to six of these variables; hospital number, name, age, sex, address, date of the crash, location of the crash, who transferred to health facility, any prior health facility visit, and name of the previous hospital visited. If the RTI case from two reporting sites matched and assumed to be duplicated, one of such matched data is retained for 
analysis. Finally, the data were consolidated on a single Excel Microsoft spreadsheet and exported into Epi-info statistical software version 7 for analysis.

Descriptive analysis such as frequencies and proportions were calculated and presented in tables, charts and trends analysis of some indicators. Odds ratios were used to calculate association with moderate to fatal injury. Variables with a greater proportion of non-completeness such as the use of alcohol, documentation of injury site, type and Abbreviated Injury Scale (AIS) score, preliminary diagnosis using International Classification of Diseases (ICD) codes were exempted from analysis as most are not documented by the attending health workers.

\section{Pre-test}

A two-day hands-on-training on data tools was conducted for supervisors and data collectors on the use of data tools, RTI surveillance system, data collection, storage, transfer, processing and dissemination. After the training and one month before the commencement of the study, the tools were pretested on RTI patients at the health facilities selected for the pilot study, for both interviewer and interviewee comprehension of the variables, acceptability, simplicity of use and time of administration. The identified corrections were made to the final draft of the questionnaire.

\section{Ethical considerations}

Ethical approval was granted by the Kaduna State Ministry of Health and Human Services Institution Review Board with reference number $\mathrm{MOH} / \mathrm{ADM} / 744 / \mathrm{Vol} .1 / 366$. Participants or relatives were duly informed and verbal or written consent or assent was obtained before the interview. Participant privacy and confidentiality was maintained, and data were anonymised before analysis.

\section{Results}

There are 31 variables on the individual case-based forms. Variables like the use of alcohol, site of injury, type of injury, Abbreviated Injury Scale (AIS) score, and International Classification of Diseases (ICD) codes for diagnosis were not collected for more than $20 \%$ of the participants and were exempted from final analysis. The overall timeliness and completeness of RTI reporting was $100 \%$ and $83.2 \%$, respectively. Furthermore, 110 records were duplicated and were deleted from the final analysis. Table 1 shows the RTI surveillance indicators monitored during the study. In overall, 667 road traffic crashes and 1,062 individuals had RTI during the study period. Of the 1,062 injured, $498(46.9 \%)$ were seen at the health facility, 381 (35.9\%) reported by the Police MTD, and 183 (17.2\%) were reported by FRSC 
Table 1

Road traffic injury surveillance indicators at Kaduna Metropolis, Kaduna Nigeria. February - July 2016

\begin{tabular}{|c|c|c|c|c|c|c|c|}
\hline Indicators & Feb. & Mar & Apr & May & Jun & Jul & Total \\
\hline Total number of crashes & 113.0 & 127.0 & 96.0 & 133.0 & 100.0 & 98.0 & 667.0 \\
\hline Total number of the injured & 168.0 & 228.0 & 172.0 & 190.0 & 148.0 & 156.0 & 1062.0 \\
\hline 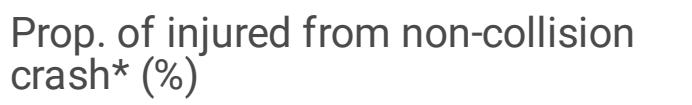 & 26.8 & 5.5 & 12.2 & 6.1 & 8.0 & 5.2 & 10.8 \\
\hline $\begin{array}{l}\text { Prop. of injured evacuated by police } \\
(\%)\end{array}$ & 27.4 & 25.0 & 43.6 & 55.3 & 50.0 & 15.4 & 35.9 \\
\hline $\begin{array}{l}\text { Prop. of injured evacuated by FRSC } \\
(\%)\end{array}$ & 26.8 & 13.6 & 19.8 & 17.9 & 14.2 & 11.5 & 17.2 \\
\hline $\begin{array}{l}\text { Prop. of injured with safety element } \\
(\%)\end{array}$ & 19.6 & 18.9 & 23.3 & 10.5 & 9.5 & 7.7 & 15.3 \\
\hline Prop. of injured with fatal injury (\%) & 16.1 & 10.1 & 10.5 & 9.5 & 9.5 & 6.4 & 10.4 \\
\hline $\begin{array}{l}\text { Prop. of fatally injured that died at } \\
\text { Health facility }(\%)\end{array}$ & 51.9 & 21.7 & 77.8 & 83.3 & 100.0 & 70.0 & 62.7 \\
\hline Timeliness of reporting & 100.0 & 100.0 & 100.0 & 100.0 & 100.0 & 100.0 & 100.0 \\
\hline Completeness of reporting & 61.0 & 68.0 & 70.0 & 100.0 & 100.0 & 100.0 & 83.2 \\
\hline
\end{tabular}

In Table 2, the median age (range) of the injured was $32(1-95)$ years, males' gender was 844 (79.5\%) and $373(35.2 \%)$ were in age group 25 to 34 years and most affected.

\section{Characteristics Of The Injured In Road Traffic Crash}


Table 2

Characteristics of the injured from road traffic crash, Kaduna metropolis, Kaduna Nigeria, February - July 2016.

\begin{tabular}{|c|c|c|}
\hline Characteristics & Fatal/severe & Total \\
\hline \multicolumn{3}{|l|}{ Age (Years) } \\
\hline$<15$ & 57 & 5.4 \\
\hline $15-24$ & 182 & 17.1 \\
\hline $25-34$ & 374 & 35.2 \\
\hline $35-44$ & 256 & 24.1 \\
\hline $45-54$ & 112 & 10.5 \\
\hline$>54$ & 81 & 7.6 \\
\hline \multicolumn{3}{|l|}{ Sex } \\
\hline Male & 844 & 79.5 \\
\hline Female & 218 & 20.5 \\
\hline \multicolumn{3}{|l|}{ Occupation } \\
\hline Trader & 209 & 19.7 \\
\hline Student & 204 & 19.2 \\
\hline Driver of motor vehicle & 112 & 10.6 \\
\hline Artisans & 76 & 7.2 \\
\hline Driver of motorcycle & 86 & 8.1 \\
\hline Civil servant & 51 & 4.8 \\
\hline Professionals-Doctors, Engr, etc., & 51 & 4.8 \\
\hline Military/Paramilitary & 49 & 4.6 \\
\hline Unemployed & 47 & 4.4 \\
\hline Housewife & 40 & 3.8 \\
\hline Farmer & 41 & 3.9 \\
\hline Driver of three-wheel vehicle & 34 & 3.2 \\
\hline Pupils & 26 & 2.5 \\
\hline Technicians & 20 & 1.9 \\
\hline Others & 15 & 1.4 \\
\hline
\end{tabular}




\begin{tabular}{|lll|}
\hline Characteristics & Fatal/severe & Total \\
\hline Mode of travelling & & \\
\hline Passenger in commercial vehicle & 217 & 20.3 \\
\hline Passenger in private vehicle & 199 & 18.7 \\
\hline Motorcycle driver & 185 & 17.4 \\
\hline Pedestrians & 181 & 17.0 \\
\hline Passengers in three-wheel vehicle (Commercial) & 80 & 7.5 \\
\hline Passengers on Motorcycle & 69 & 6.5 \\
\hline Driver in commercial vehicle & 50 & 4.7 \\
\hline Driver in private vehicle & 50 & 4.7 \\
\hline Driver in three-wheel vehicle (Commercial) & 24 & 2.3 \\
\hline Passenger at the back of truck & 6 & 0.6 \\
\hline Passenger hanging on moving vehicle & 1 & 0.1 \\
\hline Pedal cyclist & 1 & 0.1 \\
\hline
\end{tabular}

Passengers in a commercial and private vehicle were most affected accounting for 217 (20.3\%) and 199 $(18.7 \%)$ of the injured respectively.

\section{Characteristics of the road traffic crashes, post-crash management and outcome}

In Table 3, of the injured, good Samaritans or road users evacuated $469(44.2 \%)$, police MTD 381 (35.9\%), and FRSC, 183 (17.2\%). The fatally injured were 110 (10.4\%), 380 (35.8\%) had moderate injury, and 41 (3.9\%) died at crash site. Among the 110 with fatal injury, 69 (62.7\%) were rescued alive and transferred to the reporting health facilities but later died. Among the 252 motorcycle riders, 26 (10.3\%) used helmet and $136(26.4 \%)$ of the 516 vehicle users used seat belt. 
Table 3

Characteristics of the crash, site evacuation and injury severity of road traffic injury cases at Kaduna Metropolis, Kaduna Nigeria. February - July 2016.

\begin{tabular}{|c|c|c|c|c|}
\hline \multirow[b]{2}{*}{ Characteristics } & \multicolumn{4}{|c|}{ Road crash Injury severity } \\
\hline & Mild n (\%) & Moderate n (\%) & Severe/Fatal n (\%) & Total n (\%) \\
\hline \multicolumn{5}{|l|}{ Crash time } \\
\hline $00: 00-5: 59$ AM & $23(74.2)$ & $5(16.1)$ & $3(9.7)$ & $31(2.9)$ \\
\hline 6:00-11:59 AM & $117(42.9)$ & $128(46.9)$ & $28(10.3)$ & $273(25.7)$ \\
\hline 12:00-17:59 PM & 278 (61.6) & 135 (29.9) & $38(8.4)$ & $451(42.5)$ \\
\hline 18:00-23:59 PM & $154(50.2)$ & $112(36.5)$ & $41(13.4)$ & 307 (28.9) \\
\hline \multicolumn{5}{|c|}{ Crash at Metropolis centre } \\
\hline Yes & $330(60.0)$ & $171(31.1)$ & $49(8.9)$ & $550(51.8)$ \\
\hline No & $242(47.3)$ & $209(40.8)$ & $61(11.9)$ & $512(48.2)$ \\
\hline \multicolumn{5}{|l|}{ Type of road } \\
\hline Four lanes & $323(51.7)$ & $226(36.2)$ & $76(12.2)$ & $625(58.9)$ \\
\hline Two lanes & $249(57.0)$ & $154(35.2)$ & $34(7.8)$ & $437(41.1)$ \\
\hline \multicolumn{5}{|l|}{ Evacuated by } \\
\hline Police & $181(47.5)$ & $154(40.4)$ & $46(12.1)$ & $381(35.9)$ \\
\hline F.R.S.C & $83(45.4)$ & $64(35.0)$ & $36(19.7)$ & $183(17.2)$ \\
\hline Other road users & $300(64.0)$ & $143(30.5)$ & $26(5,5)$ & $469(44.2)$ \\
\hline Relatives & $8(27.6)$ & $19(65.5)$ & $2(6.9)$ & $29(2.7)$ \\
\hline \multicolumn{5}{|c|}{ Received first aid in nearby health facility } \\
\hline Yes & $7(20.0)$ & $22(62.9)$ & $7(17.1)$ & $36(3.4)$ \\
\hline No & $565(57.3)$ & $398(36.3)$ & $63(6.4)$ & $1026(96.6))$ \\
\hline Total & $572(53.9)$ & $380(35.8)$ & $110(10.4)$ & $1062(100)$ \\
\hline
\end{tabular}

Following the road traffic crash, 572 (54.0\%) were treated and discharged from the Accident \& Emergency ward, $333(31.3 \%)$ were admitted for longer hospital stay, $26(2.4 \%)$ were referred to tertiary or specialized health facility for further treatment, and 21 (2.0\%) left the hospital prior to discharge.

\section{Factors Associated With Moderate To Fatal Injury}


Table 4 shows factors associated with moderate to fatal injury. Being a driver or operator of a vehicle during the crash was associated with having a moderate to fatal RTI (OR 1.7, C.I. 1.3-2.2, p = 0.000) when compared to being a passengers or pedestrians. Moderate to fatal injury was associated with victims that were evacuated by police or FRSC (OR 1.8, C.I. 1.4-2.4, $p=0.000)$ than those evacuated by good Samaritans. And receiving first aid care in a nearby health facility before transferring to the reporting health facilities were 5 times more likely to associate with moderate to fatal injury (OR 5.1, C.I. 2.2-11.7, $p=0.000$ ). The injured, aged $<35$ years were $50 \%$ (OR $0.5, C . I .0 .4-0.7, p=0.000$ ) less likely to associate with moderate to fatal injury and being injured in a crash within the metropolis were $40 \%$ less likely to be moderate to fatal injury (OR 0.6, C.I. $0.5-0.8, p=0.000)$. 
Table 6

Associated factors with moderate to fatal injury in Kaduna Metropolis, Kaduna Nigeria. February July 2016.

\section{Moderate to fatal injury}

$\begin{array}{lllll}\text { Risk Factors } & \text { Yes } & \text { No } & \text { Total }(95 \% \text { C.I }) & \text { p value }\end{array}$

Age $<35$ years

No

$248(50.6) \quad 201(35.1) \quad 449(42.3) \quad$ ref

Yes

$242(49.4)$

$371(64.9)$

$613(57.7)$

$0.5(0.4,0.7)$

0.000

Sex

Female $\quad 91(18.6) \quad 127(22.2) \quad 218(20.5) \quad$ ref

$\begin{array}{llllll}\text { Male } & 399(81.4) & 445(77.8) & 844(79.5) & 1.3(0.9,1.7) & 0.166\end{array}$

\section{Crash at metropolis centre}

$\begin{array}{llllll}\text { No } & 270(55.1) & 242(42.3) & 512(48.2) & \text { ref } & \\ \text { Yes } & 220(44.9) & 330(57.7) & 550(51.8) & 0.6(0.5,0.8) & 0.000\end{array}$

Travelling in a commercial or private vehicle

$\begin{array}{lllll}\text { Pedestrian } & 89(18.2) & 92(16.1) & 181(17.0) & \text { ref }\end{array}$

$\begin{array}{llllll}\text { Commercial } & 157(32.0) & 220(38.5) & 377(35.5) & 0.7(0.5,1.1) & 0.113\end{array}$

$\begin{array}{lllll}\text { Private } & 244(49.8) & 260(45.4) & 504(47.5) & 1(0.7,1.4)\end{array}$

Status during the crash

$\begin{array}{lllll}\text { Passengers } & 234(47.8) & 337(58.9) & 571(53.8) & \text { ref }\end{array}$

$\begin{array}{llllll}\text { Drivers/operators } & 167(34.1) & 143(25.0) & 310(29.2) & 1.7(1.3,2.2) & \mathbf{0 . 0 0 0}\end{array}$

$\begin{array}{llllll}\text { Pedestrians } & 89(18.2) & 92(16.1) & 181(17.0) & 1.4(1.0,1.9) & 0.060\end{array}$

\section{Type of road}

Less four lane road $\quad 188(38.4) \quad 249(43.5) \quad 437(41.1) \quad$ ref

$\begin{array}{lllll}\text { Four lane road } \quad 302(61.6) & 323(56.5) & 625(58.9) & 1.2(1.0,1.6) & 0.100\end{array}$

\section{Use safety element}

$\begin{array}{llllll}\text { Yes } & 82(16.7) & 80(14.0) & 162(15.3) & \text { ref } & \\ \text { No } & 408(83.3) & 492(86.0) & 900(84.7) & 0.8(0.6,1.1) & 0.247\end{array}$

Received first aid at health facility

$\begin{array}{lllll}\text { No } & 461(94.1) & 565(98.8) & 1026(96.6) & \text { ref }\end{array}$ 


\begin{tabular}{|c|c|c|c|c|c|}
\hline \multicolumn{6}{|c|}{ Moderate to fatal injury } \\
\hline Yes & $29(5.9)$ & $7(1.2)$ & $36(3.4)$ & $5.1(2.2,11.7)$ & 0.000 \\
\hline \multicolumn{6}{|c|}{ Evacuated by Police or FRSC } \\
\hline No & $190(38.8)$ & $308(53.9)$ & $498(46.9)$ & ref & \\
\hline Yes & $300(61.2)$ & $264(46.2)$ & $564(53.1)$ & $1.8(1.4,2.4)$ & 0.000 \\
\hline
\end{tabular}

\section{Discussion}

This study demonstrates the feasibility of a multidisciplinary and integrated RTI surveillance system in Kaduna Nigeria. Similar studies have reported the integration of two or more RTI surveillance data [1921]. The integration of RTI surveillance data from multidisciplinary sources will strengthen the surveillance system [20, 21]. For example, RTI data collected from single sources like the police, FRSC, emergency services, and morbid anatomy or pathology department are good for providing the number of fatalities, pre-hospital care, on-the-spot deaths, intoxication and use of safety element which may not be available in hospital records [22]. This study shows that multidisciplinary RTI data sources can be integrated and used for action on RTI prevention in a low resource setting like Kaduna Nigeria. This will obliterate the disadvantages associated with a single source RTI data.

Succinctly, in this study, FRSC and the police only reported $17 \%$ and $36 \%$ of the people injured, respectively. This discrepancy has been shown to exist between organizations [23], due to their different focus of data collection. Therefore, relying on data from these agencies for planning on holistic RTI prevention may be defective $[23,24]$. Though a study in Saudi Arabi attributed the differences to the use of different data tools, data collection methods [24], the organizational context for which data are collected and used. But this was not the case in this study as a single data collection tool was used and for a single purpose of surveillance and not for litigations or insurance. Other defects of a sole RTI data source was under-detection by as shown in Iran [23]. The under-reporting of RTI was shown in a study the police that under-reported less severe RTI cases $[19,21]$. Sometimes, the reporting agency undermines the severity of the RTI for example, less severe cases reported by the police and insurance [25] were fatal injury at the hospital [21]. The implication of the under-reporting greatly impacts on the current estimates of RTI burden and misguided prioritization of preventative initiatives [21].

A comprehensive data collection system for road traffic accidents should cover all the data collection sources [23] like the police, FRSC and Ambulance services that clearly records RTC description, and health facilities that provided care for the injured [25]. In this study, all the three sectors used similar tools that comprise the variables of interest to all sectors adapted from their original data tool. But variables like the use of alcohol, site of injury, type of injury, Abbreviated Injury Scale (AIS) score, and International Classification of Diseases (ICD) codes for diagnosis were not adequately recorded. This may be due to the lack of training on how to report these variables. One key factor hindering multidisciplinary RTI surveillance was database linkage [21] and merging of multi-source RTI data to avoid duplication and 
wrong coding. This was demonstrated in the study from the Dominican Republic where $20 \%$ of data recorded were duplicated [25] compared to more than $9 \%$ duplicated records experienced in this study. In this study, a deterministic approach of data linkage was used but a semiautomated approach has been recommended to reduce data duplication [25].

Majority of the road traffic crash victims in this study were between the ages of 15-44 years with male preponderance. Similar to previous studies in Nigeria, this age group were in years of productivity resulting in high economic loss [26]. Most of the young population in this study were engaged in the driving of either the three-wheel vehicles or motorcycles for commercial purposes and found to have a mild injury. This was different from a study that found that most fatal RTI cases were in this age group [11] that can be prevented if safety elements were used. The use of helmet by motorcycle riders reported in this study was lower than $24.7 \%$ reported for the motorcyclist in another Nigeria study but far better than some previous studies $[7,27]$. It further strengthens the fact that the use of safety elements is poor in Nigeria. However, the use of safety belt in this study was better than previous studies, $26.4 \%$ of vehicle users compared to $11 \%-13 \%$ use seat belts during the crash $[11,26,28]$. This calls for enforcement of the consistent use of these safety elements and other preventive measures of road traffic injury in Nigeria.

Some limitations to this study were the inability of reporting sites to adequately report variables like the use of alcohol, injury sites, Abbreviated Injury Scale (AIS) score, diagnosis of injury type using International Classification of Diseases (ICD) codes by the reporting sites. This was due to a lack of training on these variables. Though deterministic linkage approach was used to link data and identify data duplication for deletion. This may not be perfect and could have been avoided if a citizen's unique national identification number is used but was not operating in Nigeria. Also, this study may not have reported all road traffic crashes in Kaduna metropolis during the study as some mild RTI might have not been caught by this integrated surveillance system but the system is more reliable to generate a robust RTI data for action than RTI data from a sole agency.

\section{Conclusion}

This study confirmed the feasibility of an integrated and multidisciplinary RTI data sources for injury surveillance in low resource setting like Kaduna metropolis in Nigeria. This pilot test can be scale up and will generate robust data to monitor and evaluate the progress of well-tailored interventions to improve RTI surveillance and prevention. This will improve the identification, collection, and reporting of RTI surveillance data needed for action to meet the SDG 3.6 target.

\section{List Of Abbreviations}

AIS - Abbreviated Injury Scale;

A \& E - Accident and Emergency 
BDTH - Barau Dikko Teaching Hospital

FRSC - Federal Road Safety Corps

ICD - International Classification of Diseases

LMIC - Low-and Middle-Income Countries

MTD - Motor Traffic Division

NARH - Nigerian Army Reference Hospital

RTA - Road Traffic Accident

RTC - Road Traffic Crash

RTI - Road Traffic Injury

SDG - Sustainable Development Goal

SGCH - St. Gerald Catholic Hospital

WHO - World Health Organizations

\section{Declarations}

\section{Ethics approval and consent to participate}

Ethical approval referenced MOH/ADM/744/Vol.1/366 was obtained from the Ethical Review Committee of Ministry of Health, Kaduna State, Nigeria. The approval was granted by the FRSC, Kaduna State Police motor traffic division and the administrators of the three major health facilities in Kaduna metropolis.

Consent for publication: Not applicable

\section{Availability of data and materials}

The datasets used and/or analysed during the current study are available from the corresponding author on reasonable request.

\section{Competing interests}

The authors declared that they have no competing interests.

\section{Funding}

This study was supported by Independent Contractor Services Agreement funded by the United States Centres for Disease Control and Prevention through Task Force for Global Health, TEPHINET non- 
communicable disease mini-grant 2016. Its contents are solely the responsibility of the authors and do not necessarily represent the official views of the United States Centres for Disease Control and Prevention or the Department of Health and Human Services.

\section{Authors' contributions:}

OJB conceived the study and was responsible for its design, data collection, analysis, and interpretation; and writing the manuscript.

\section{Acknowledgements}

The authors thank everyone that supported the implementation of this study. I acknowledged the contribution of $\mathrm{Dr}$ C. Ukpaka for his supervisory role during the project and Dr Aisha Abubakar, Kaduna State Epidemiology for her support during the implementation of the project. We also thank all the stakeholders of road traffic injury surveillance in Kaduna State and study participants for their cooperation. We used Mendeley reference manager and Epi info software in this manuscript.

\section{References}

1. Agbeboh G, Osarumwense O. Empirical analysis of road traffic accidents: A case study of Kogi State, North-Central Nigeria. Int J Phys Sci [Internet]. 2013;8(40):1923-33. Available from: http://www.academicjournals.org/journal/IJPS/article-full-text-pdf/BB6BAE141841.

2. $10.1093 /$ epirev/mxq009

Chandran A, Hyder AA, Peek-Asa C. The Global Burden of Unintentional Injuries and an Agenda for Progress. Epidemiol Rev [Internet]. 2010;32(1):110-20. Available from: http://epirev.oxfordjournals.org/cgi/doi/10.1093/epirev/mxq009.

3. World Health Organization. Global Status Report on Road Safety 2018. [Internet]. Geneva; 2018. Available from: https://www.who.int/violence_injury_prevention/road_safety_status/2018/en/.

4. World Health Organization. Global status report on road safety 2015 [Internet]. Geneva 27, Switzerland.; 2015. Available from: http://www.who.int/violence_injury_prevention/road_safety_status/2015.

5. United Nations Economic Commission for Europe Inland Transport Committee. Consolidated Resolution on Road Traffic. New York and Geneva; 2010.

6. Razzak J, Shamim M, Mehmood A, Hussain S, Ali M, Jooma R. A successful model of road traffic injury surveillance in a developing country: process and lessons learnt. BMC Public Health [Internet]. 2012;12(1):357. Available from: http://www.biomedcentral.com/1471-2458/12/357.

7. Nwadiaro HC, Ekwe KK, Akpayak IC, Shitta H. Motorcycle injuries in north-central Nigeria. Niger J Clin Pract. 2011;14(2):10-3.

8. World Health Organization Regional Office for Africa. Status of road safety in the African region. Congo Brazzaville; 2018. 
9. World Health Organization. Global Status Report on Road Safety 2013: Supporting a decade of action. Geneva 27, Switzerland.; 2013.

10. Kolawole G. Spatial Trend and Management of Road Traffic Accident Fatalities in Nigeria. Acad J Interdiscip Stud. 2015;4(1):25-34.

11. World Health Organization. Road Safety in the African Region the Facts 2013 [Internet]. 2013. Available from:

http://www.who.int/violence_injury_prevention/road_safety_status/2013/report/factsheet_afro.pdf.

12. World Helth Organization. Resolution adopted by the General Assembly on 2 March 2010. Vol. 64/255, World Health Assembly A/RES/64/255. Geneva 27, Switzerland.; 2010.

13. World Health Organization. Brasilia Declaration [Internet]. Second Global High-level Conference on Road Safety: Time for Results Brasilia, 18-19 November 2015 PP1. 2015. Available from: http://www.who.int/violence_injury_prevention/road_traffic/Brasilia_Declaration/en/.

14. Holder Y, Peden M, Krug E et al, editors, editor. Injury Surveillance Guidelines. WHO/NMH/VIP/01.02. Geneva. World Health Organization: Centers for Disease Control and Prevention, Atlanta, USA, World Health Organization;; 2001.

15. Espitia-Hardeman V, Paulozzi L Injury Surveillance Training Manual. Centers for Disease Control and Prevention, National Center for Injury Prevention and Control; Atlanta, Georgia; 2005.

16. Lekwot Vivian E, Dyaji Leo N, Orji. Public Health effects from vehicular emissions in Kaduna metropolis, Kaduna State, Nigeria. Int J Innov Environ Stud Res 1. 2013;1(1):21-30.

17. World Health Organization. Injuries, Traffic [Internet]. [cited 2015 Oct 19]. Available from: http://www.who.int/topics/injuries_traffic/en/.

18. World Health Organization. World report on road traffic injury prevention. Margie Peden, Richard Scurfield, David Sleet, Dinesh Mohan Adnan A. Hyder EJ and CM, editor. Geneva 27, Switzerland.; 2004.

19. Chini F, Farchi S, Ciaramella I, Antoniozzi T, Rossi P, Camilloni L, et al. Road traffic injuries in one local health unit in the Lazio region: results of a surveillance system integrating police and health data. Int J Health Geogr [Internet]. 2009;8(1):21. Available from: http://www.ijhealthgeographics.com/content/8/1/21.

20. Medina YR, Espitia-Hardeman V, Dellinger AM, Loayza M, Leiva R, Cisneros G. A road traffic injury surveillance system using combined data sources in Peru. Rev Panam Salud Publica/Pan Am J Public Heal [Internet]. 2011;29(3):191-7. Available from: http://www.scopus.com/inward/record.url? eid=2-s2.0-79954435039\&partnerID=tZOtx3y1.

21. Taylor P, Petridou ET. Linking Emergency Medical Department and Road Traffic Police Casualty Data. A Tool in Assessing the Burden of Injuries in Less Resourced Countries Linking Emergency Medical Department and Road Traffic Police Casualty Data : A Tool in Assessing the Burden. Traffic Inj Prev. 2009;10:37-43.

22. Shah B. Workshop on Development of a Feasibility Module for Road Traffic Injury Surveillance. New Delhi: Ansari Nagar; 2006. 
23. Taylor P, Abdalvand A. Necessity of an Integrated Road Traffic Injuries Surveillance System: A Community-Based Study Necessity of an Integrated Road Traffic Injuries Surveillance System : A Community-Based Study. Traffic Inj Prev. 2011;12:358-62.

24. Barrimah I, Midhet F, Sharaf F. Epidemiology of Road Traffic Injuries in Qassim Region, Saudi Arabia : Consistency of Police Abstract : Road traffic injuries (RTI) are a major public health problem worldwide and a major cause of death and disability. Furthermore, according to the W. 2012;6(1).

25. Puello a, Bhatti J, Salmi LR. Feasibility of road traffic injury surveillance integrating police and health insurance data sets in the Dominican Republic. Rev Panam Salud Publica [Internet]. 2013;34(1):416. Available from: http://www.ncbi.nlm.nih.gov/pubmed/24006019.

26. Chalya PL, Mabula JB, Dass RM, Mbelenge N, Ngayomela IH, Chandika AB, et al. Injury characteristics and Outcome of Road traffic crash victims at Bugando Medical Centre in Northwestern Tanzania. J Trauma Manag Outcomes [Internet]. 2012;6(1):1. Available from: http://www.traumamanagement.org/content/6/1/1.

27. Adoga AA, Ozoilo KN. The epidemiology and type of injuries seen at the accident and emergency unit of a Nigerian referral center. J Emerg Trauma Shock. 2014;7(2).

28. Idris SH, Sambo MN, Gambo H, Hassan A. Factors affecting self-reported use of seat belt among commercial vehicle drivers in Gusau metropolis Zamfara State North-western Nigeria. Int J Inj Contr Saf Promot. 2013;20(4):380-4. 